\title{
A Review of Floor Heating Research in Japan
}

\author{
Shin-ichi Watanabe \\ Department of Architecture, Daido Institute of Technology, Japan, \\ 40 Hakusui-cho, Minami-ku, Nagoya, 457-8532, Japan \\ (received on April 16, 2001; accepted on Aug. 16, 2001)
}

\begin{abstract}
Floor heating systems have been recently become popular in Japanese houses. Many researchers have conducted their researches on floor heating from the viewpoint of creating a comfortable living environment in winter. They have gotten valuable information for architects, engineers and occupants. The objective of this paper is to review the previous studies on the effect of floor heating systems on human thermal comfort in Japan. Aims and findings of each research group are summarized based on research papers presented from 1975 to 1997 in Japan. Comfort zones, recommended conditions and limit conditions for humans using the floor heating system proposed by each researcher were illustrated in the charts consisting of air temperature and floor surface temperature. This review will contribute to the progress of future floor heating research.
\end{abstract}

Key words: review, floor heating, comfort zone, human body, Japan

\section{Introduction}

Recently, floor heating systems have been become popular in Japanese houses. Generally, the floor heating system is recognized as providing a high amenity environment in rooms in Japan because the vertical air temperature difference is small and occupants feel it comfortable to receive thermal radiation from the heated floor and conductive heat from the contacted floor surface. Many researchers have carried out research on floor heating from different points of view, i.e. determining the thermal comfort zone, numerical simulation for evaluating the system efficiency, system development of floor heating and so on. Consequently, they have provided valuable information for architects, engineers and occupants. Although similar researches have been conducted in Europe and America, their findings do not necessarily applying to Japan because the life styles in both areas are different. People in Japan and Korea are used to sitting on a floor. This study reviews papers on floor heating presented in Japan from 1975 to 1997. The important point of this paper is to summarize the progress of floor heating research by each research group. Comfort zone, recommendations and limit conditions for the floor heating are illustrated in the charts which show with air temperature and floor temperature.

\section{Trend of Floor Heating Research}

The following sources were used as review materi- als: 1) Summaries of Technical Papers of Annual Meeting Architectural Institute of Japan (AIJ), 2) Journal of Architecture, Planning and Environmental Engineering (Transactions of AIJ), 3) Transactions of the Society of Heating, Air-Conditioning and Sanitary Engineers of Japan (Transactions of SHASE), 4) Summaries of Technical Papers of Annual Meeting the Society of Heating, Air-Conditioning and Sanitary Engineers of Japan (SHASE), 5) Japanese Journal of Biometeorology, 6) Proceedings of Symposium on Human-Environment System. The original papers and reports submitted to the literature from 1975 to 1997 were investigated. The number of papers regarding floor heating is 131. Figure 1 shows the number of papers with passage of the year. Although the number of papers doesn't always mean the progress of the research, it may indicate the degree of the interest. Though the researches on floor heating were also reported before 1975 in domestic and overseas, papers after 1975 were investigated in this review for the reason to obtain easily. A lot of researches regarding the amenity of floor heating have been performed since the beginning of 1980's. In 1989, the SHASE set up "Research Committee on Amenity Evaluation of Floor Heating". In 2000, the Society of Human-Environment System held a symposium "International Standards for Non-Uniform Thermal Environments-With Respect to Floor Heating Systems". 


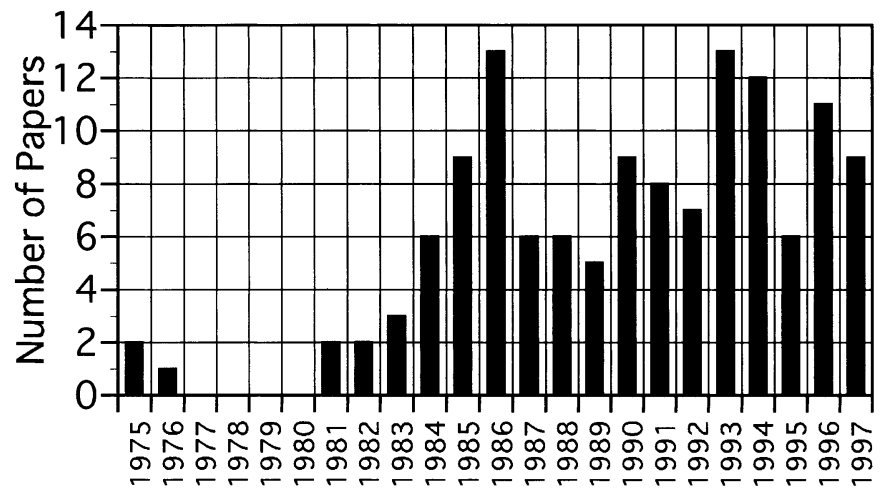

Fig. 1. Number of papers concerning floor heating.

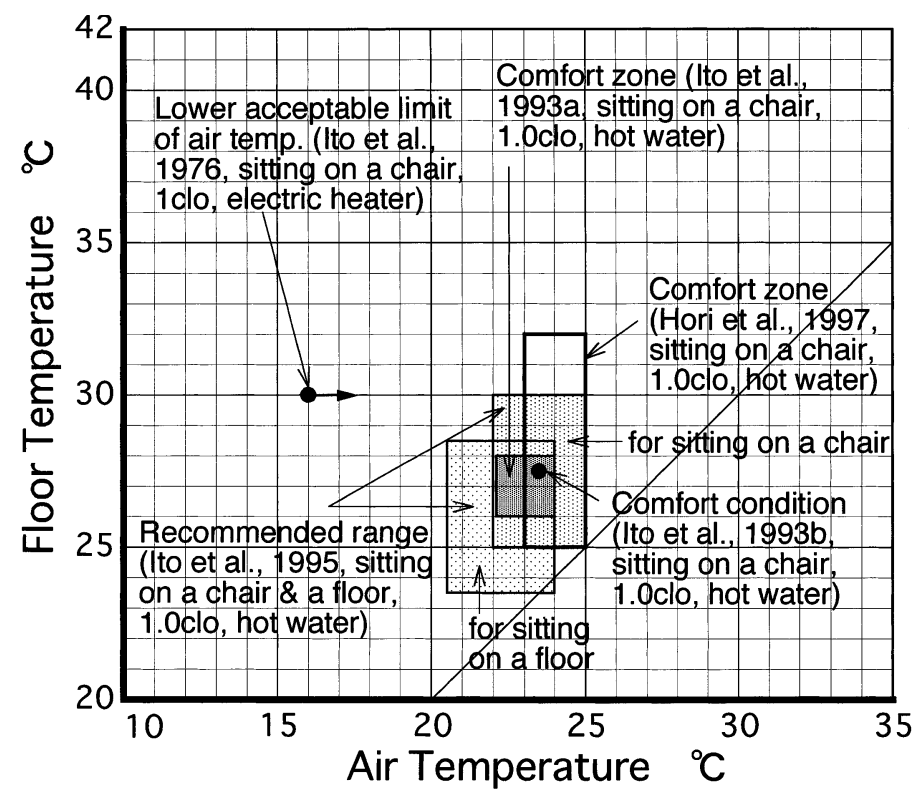

Fig. 2. Comfort zones, recommendations, and limit conditions of the floor heating (Tokyo Metropolitan University).

\section{Features and Progress in Each Research Group}

In order to clarify the aims and features of each research group, the papers are analyzed. Comfort zones, recommended conditions and limit conditions, which can be expressed in the combination of air temperature and floor temperature, are illustrated in the charts. The legends in the charts show the following: author(s), published year, body posture of subject, thermal insulation value of clothing (in clo unit) and heat source (electric or hot water). Since all papers except one are written in Japanese, the terminology in this review refers to original titles and abstracts written in English.

\section{1) Tokyo Institute of Technology and Toyohashi Uni- versity of Technology}

This group has carried out a continuous series of subjective experiments in order to clarify the effect of air temperature, air flow, humidity and thermal radiation upon the human body using an artificial climatic wind tunnel. In 1975, the first paper on the effect of floor temperature on the human responses was presented by Inoue et al. (1975). Maintaining the operative temperature at $23^{\circ} \mathrm{C}, 25^{\circ} \mathrm{C}$ and $28^{\circ} \mathrm{C}$, the influence of asymmetric thermal radiation fields on the human body was examined by Kurazumi et al. (1985) and Kobayashi et al. (1986). Hirayama et al. (1984) reported that the clothed subject felt thermal neutrality when the operative temperature was $23^{\circ} \mathrm{C}$ and mean skin temperature was $33^{\circ} \mathrm{C}$. Yamaguchi et al. (1985) studied the effect of shielding of radiant heat due to a desk in office space. Hirayama et al. (1985) developed a modified operative temperature including the effect of heat conduction between human body and floor surface.

\section{2) Tokyo Metropolitan University (See Fig. 2)}

This group has conducted comprehensive research concerning the effect of asymmetric radiation on thermal comfort (Ito et al., 1985; Ito et al., 1986a; Ito 


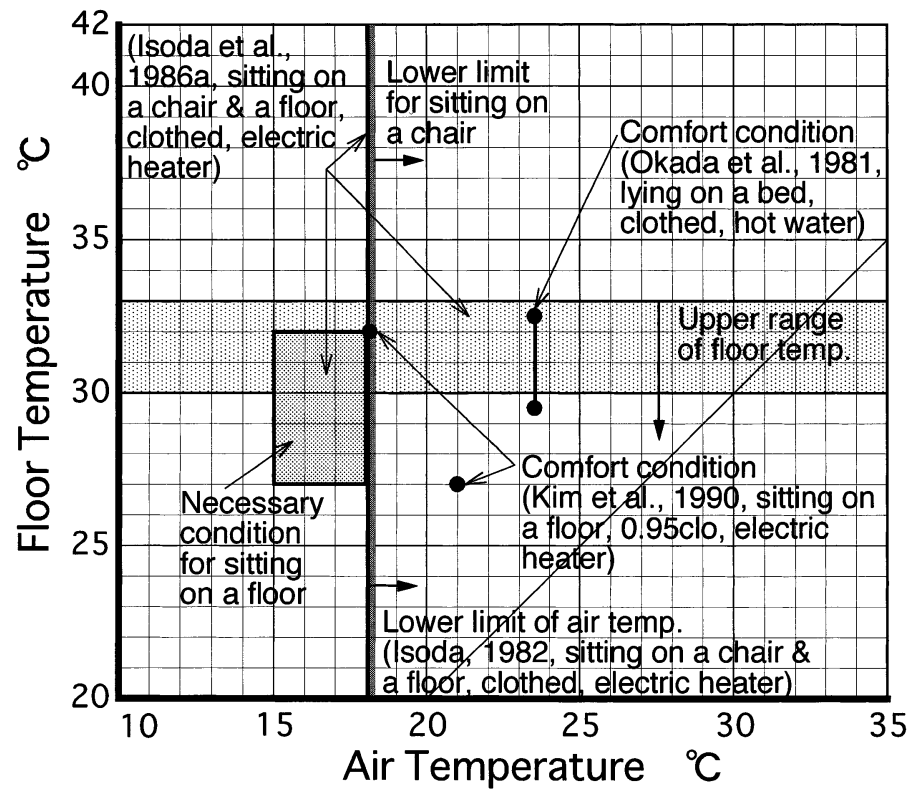

Fig. 3. Comfort zones, recommendations, and limit conditions of the floor heating (Nara Women's University).

et al., 1986b; Ito et al., 1987a; Ito et al., 1987b; Ito et al., 1989) . An experimental study for floor heating was performed in 1976. Ito et al. (1976) reported that the subjects voted thermal neutrality when the combination of floor temperature was $30^{\circ} \mathrm{C}$ and air temperature was $16^{\circ} \mathrm{C}$ in a room with floor heating. This group conducted subjective experiments to clarify the amenity of floor heating under various combined conditions of floor temperature and air temperature. Sunaga et al. (1992) obtained tolerance limits and comfort zone in the combination of air temperature and floor temperature from analysis of previous studies in Japan. Based on the experimental data, comfort condition for clothed person sitting on a chair $\left(27.5 / 23.5^{\circ} \mathrm{C}\right.$ floor/air temperature) and comfort range for clothed person sitting on a chair (26-28/ $22-24^{\circ} \mathrm{C}$ floor/air temperature) were proposed (Ito et al., 1993a; Ito et al., 1993b). Ito et al. (1994a) examined the relationship between thermal sensation of whole body and local thermal sensation, and pointed out that local thermal sensation at head, arm and back affects thermal sensation of the whole body in a hot environment, while that the sensation at arm, back and foot affects the whole body sensation in a cold environment. Ito et al. (1994b) discussed the equivalent thermal comfort line by the combination of floor temperature and air temperature. Ito et al. (1995) proposed two comfort ranges; $25-30 / 22-25^{\circ} \mathrm{C}$ floor/air temperature for sitting on a chair, 23.5-28.5/20.5$24^{\circ} \mathrm{C}$ floor/air temperature for sitting on a floor. Hori et al. (1997) proposed to predict the thermal comfort condition using the local thermal sensation based on the experiments in which over 700 subjects participated. Kabata et al. (1993) clarified that the optimum condition depends on the heating system, e.g. convective heating or radiant heating. Ito et al. (1989) also dealt with radiant cooling. The effect of posture (Kato et al., 1995) and the effect of the installation site of radiant panels on thermal comfort (Kato et al., 1994) were also examined.

\section{3) Nara Women's University (See Fig. 3)}

Research on floor heating started from the viewpoint of design for the sleep environment. Okada et al. (1981) reported comfortable floor temperature $\left(29.5-32.5^{\circ} \mathrm{C}\right)$ in the bed with the air temperature at $23.5^{\circ} \mathrm{C}$. Isoda (1982) carried out experiments in which subjects could choose the preferred floor temperature and air temperature. Isoda et al. (1986a) investigated the effects of the floor and air temperatures on physiological and psychological responses experimentally. Comfort conditions for the subject sitting on a heated floor (combination of air temperature 15$18^{\circ} \mathrm{C}$ and floor temperature $27-32^{\circ} \mathrm{C}$ ), lower limit of air temperature of $18^{\circ} \mathrm{C}$ for sitting on a chair, upper limit of floor temperature of $30-33^{\circ} \mathrm{C}$ were proposed as shown in Fig. 3. Researches on the amenity of the floor heating were carried out from the following viewpoints; difference of posture (Isoda et al., 1986b; Lee et al., 1997a), direct or indirect exposure to heated floor (Kim et al., 1987; Kim et al., 1990), difference of finishing materials of floor (Kim et al., 1989), radiant heating or cooling (Lee et al., 1997b; Mitsuda et al., 1997) and difference of heating system (Isoda et al., 1996). Enomoto et al. (1994) conducted an experimental study of the effect of radiant heating on the elderly. This research is remarkable, since many research groups mainly used young sub- 


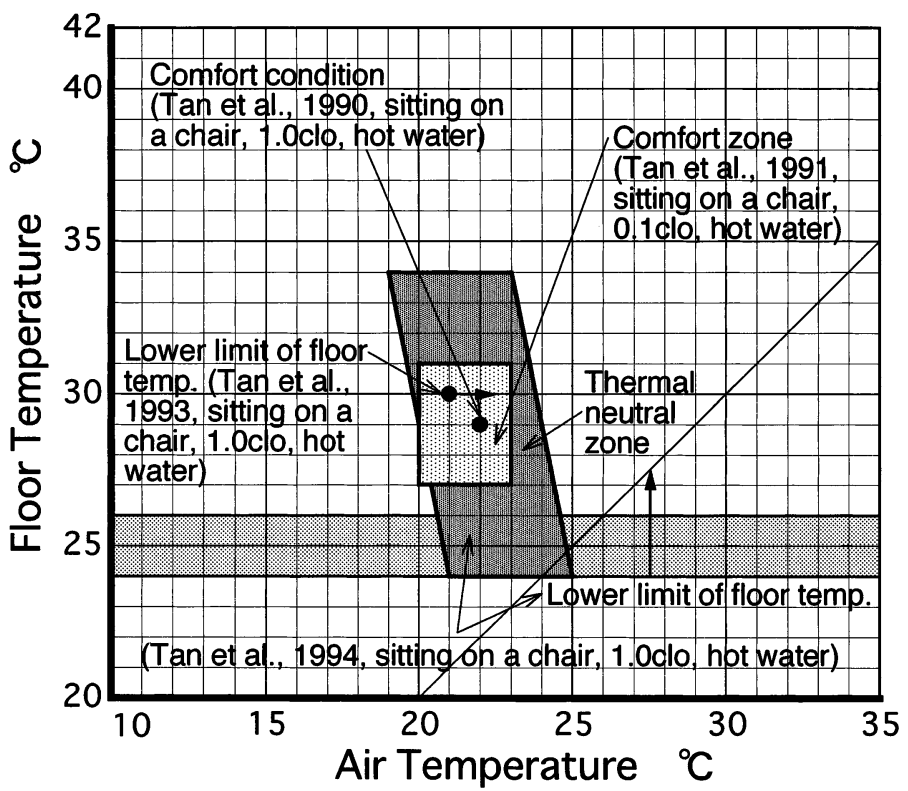

Fig. 4. Comfort zones, recommendations, and limit conditions of the floor heating (The University of Tokyo).

jects.

\section{4) Yokohama National University}

Kawashima et al. (1982) investigated physiological and psychological effects of floor heating systems using electric panel heaters and hot water panel heaters. Fukai and Emura (1996) reported that the thermal sensation of the contacted part and thermal comfort depend on the different thermal resistance of floor materials. The skin temperature in contact with the floor rose and subject felt warm, when the heat source temperature became higher or the thermal resistance of floor material was higher, even though floor and air temperature conditions were same (Fukai and Emura, 1997). Fukai (1997) also studied the effect of floor cooling on the physiological and psychological responses, and clarified that subjects felt the thermal neutrality when the skin temperature in contact with the floor was approximately $32^{\circ} \mathrm{C}$.

\section{5) The University of Tokyo (See Fig. 4)}

This group has carried out a series of research projects regarding the effect of thermal variables such as air temperature and thermal radiation on thermal comfort (Tanaka et al., 1984; Mitsumine et al., 1985; Shimizu et al., 1986; Mitsumine et al., 1986). This group participated in the 'Research Committee on Amenity Evaluation of Floor Heating' after the Society of Heating, Air-Conditioning and Sanitary Engineers of Japan in 1989, and through the activity of the research committee the following results were obtained: comfort condition for sitting on a chair was $29 / 22^{\circ} \mathrm{C}$ floor/air temperature (Tan et al., 1990), comfort range for sitting on a chair was $27-31 / 20-23^{\circ} \mathrm{C}$ floor/air temperature (Tan et al., 1991), lower limit of air temperature was $21^{\circ} \mathrm{C}$ at floor temperature of $30^{\circ} \mathrm{C}$ (Tan et al., 1993). Tan et al. (1994) indicated a thermal neutral range based on the thermal sensation of the contacted segment, thermal sensation of the whole body and comfort votes as shown in Fig. 4. Tan et al. (1995) also studied the tolerance of cold draft in relation to floor heating from subjective experiments.

\section{6) Osaka City University (See Fig. 5)}

Emura and Saito (1985) examined the effect of the heating of the sole of the foot on the physiological responses by subjective experiments. They concluded that the rectal temperature did not drop when the sole of the foot was heated. This group participated in the 'Research Committee on Amenity Evaluation of Floor Heating' after the SHASE, and performed remarkable research. Emura (1990) surveyed the permissible surface temperatures for floor heating as reported by previous researches over the world. The threshold of the moderate temperature burn can be estimated in the relation between contact surface temperature and contact time. In order to prevent the moderate temperature burn, Emura recommended that the floor temperature should be set less than $40^{\circ} \mathrm{C}$. Yagou et al. (1991) proposed thermally neutral conditions and limiting conditions based on subjective experiments in which subjects were exposed for 4 hours; thermally neutral condition for sitting on a chair was $30 / 22-23^{\circ} \mathrm{C}$ floor/air temperature, thermally neutral condition for sitting on a floor was $25.5 / 20^{\circ} \mathrm{C}$ floor/air temperature, lower limit of air temperature was $20-21^{\circ} \mathrm{C}$, upper limit of the floor 


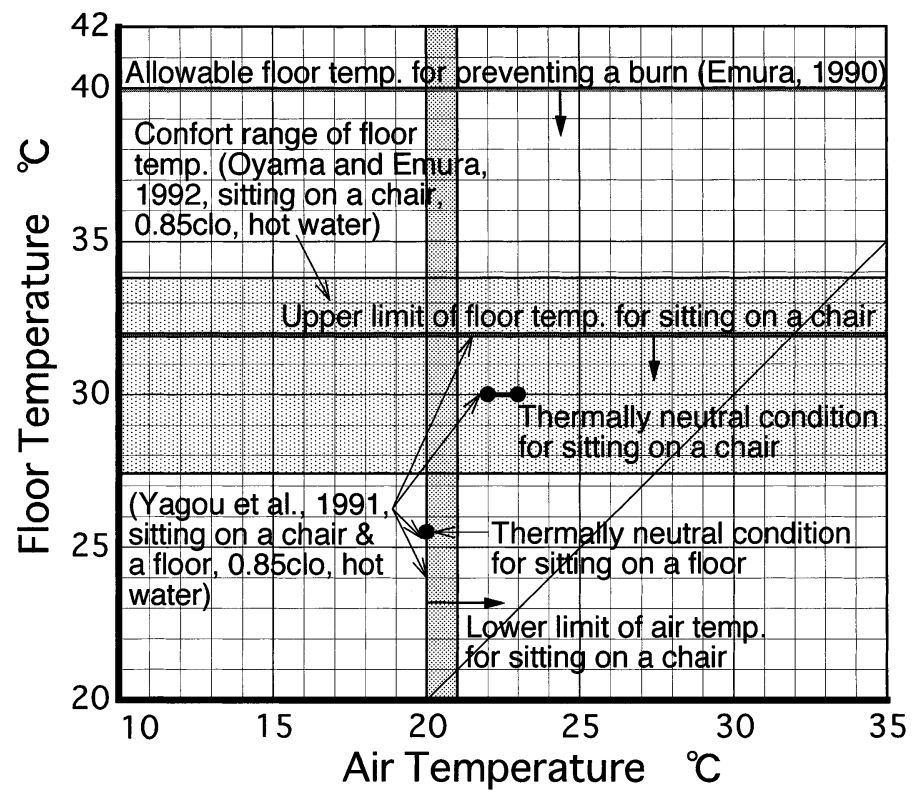

Fig. 5. Comfort zones, recommendations, and limit conditions of the floor heating (Osaka City University).

temperature was $32^{\circ} \mathrm{C}$. Oyama and Emura (1992) indicated that the local thermal sensation of peripheral parts such as arms, legs and ankles affected the thermal sensation of the whole body. Oyama et al. (1993a) proposed the optimum ranges of floor temperature, globe temperature and mean skin temperature; $27.85-33.23^{\circ} \mathrm{C}, 23.28-25.46^{\circ} \mathrm{C}, 32.65-33.7^{\circ} \mathrm{C}$, respectively. A database obtained from subjective experiments through the research committee activities was constructed (Emura, 1993; Emura et al., 1993; Oyama et al., 1993b). Zheng et al. (1995) studied the floor heating safety by investigating the contact temperature through experiment and heat transfer analysis using the model of contact body position. Based on previous domestic and overseas researches, Zhang et al. (1996) statistically investigated the recommended conditions and tolerable floor surface temperature for both the young and the elderly.

\section{7) Building Research Institute (See Fig. 6)}

This group has carried out a series of researches to clarify the effect of floor heating on thermal comfort. Based on domestic and overseas studies, Bogaki (1985) outlined allowable limits and comfortable conditions for floor heating systems. Bogaki (1986) concluded that the combination of the floor surface temperature range from 25 to $30^{\circ} \mathrm{C}$ and air temperature range from 18 to $20^{\circ} \mathrm{C}$ gives a thermally neutral and comfortable zone for floor heating especially when the persons were sitting on the floor or a chair with no slippers. This author compared the influence of age between elderly and young, and pointed out that the elderly would wear $0.4-0.5$ clo clothing more than the young. This group participated in the 'Re- search Committee on Amenity Evaluation of Floor Heating' after the SHASE, and through the activity a series of subjective experiment was carried out. Bogaki and Osawa (1990) proposed the combination of floor temperature of $24^{\circ} \mathrm{C}$ and air temperature of $19^{\circ} \mathrm{C}$ as a permissible condition for the elderly and the young. Bogaki (1991) proposed a goal condition combining of floor temperature from 25 to $27^{\circ} \mathrm{C}$ and air temperature from 19 to $20^{\circ} \mathrm{C}$ through subjective experiments using the elderly and the young, in the posture of sitting on a chair and a floor. Bogaki (1994) showed the optimum zone and goal condition for designing floor heating shown in Fig. 6 by experiments using college aged subjects.

\section{8) Waseda University}

Kimura et al. (1987) carried out subjective experiments using floor heating panels. By calculating the modified temperature (MT) from the measured data, thermal comfort in the room with floor heating system was evaluated. MT was defined as the air temperature of $50 \% \mathrm{rh}, 0.1 \mathrm{~m} / \mathrm{s}$ mean air velocity, $0.6 \mathrm{clo}, 1.0$ met and mean radiant temperature equaled to the air temperature, which would provide the same thermal sensation as under the actual thermal condition and was calculated by Fanger's comfort equation (Tanabe and Kimura, 1986). Kimura et al. (1988a) measured the energy consumption necessary for maintaining $\mathrm{PMV}=0$ in the occupied zone using radiant panel heating, hot air heating and floor heating, respectively. The effect of the difference of heating system on the thermal comfort was examined by subjective experiments (Kimura et al., 1988b, 1988c). Subjective experiments focused on the amenity of floor 


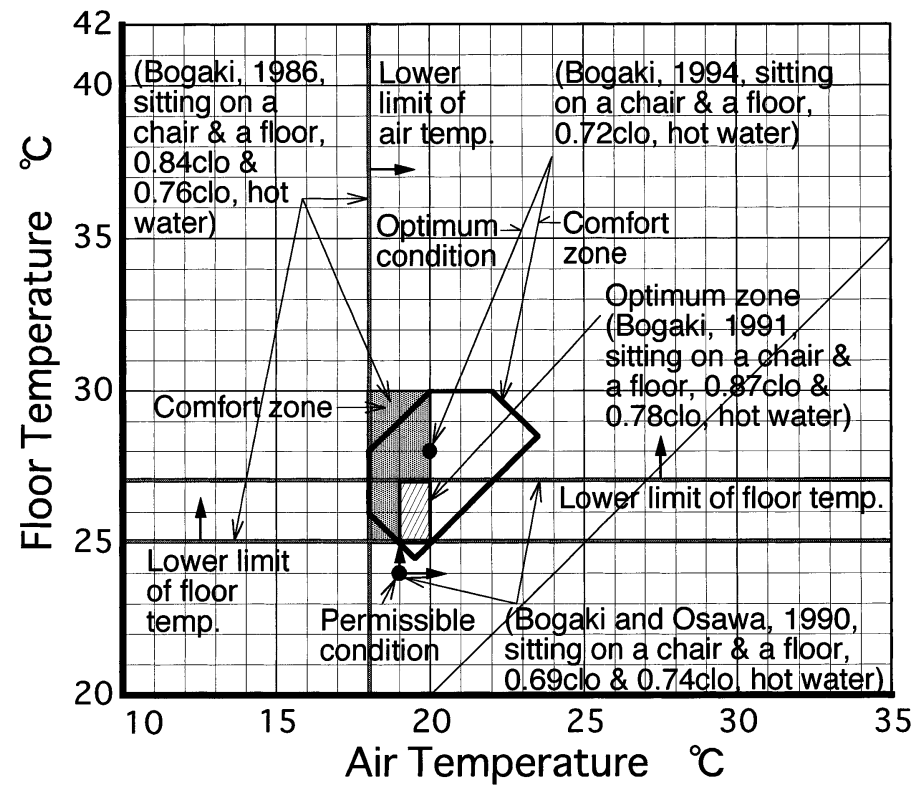

Fig. 6. Comfort zones, recommendations, and limit conditions of the floor heating (Building Research Institute).

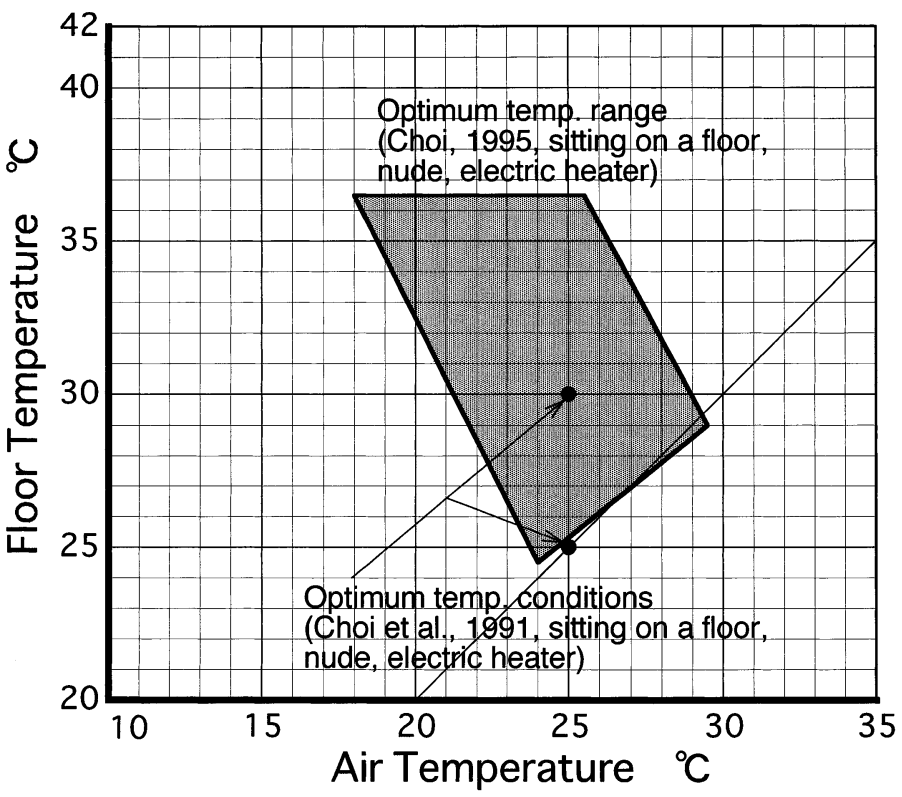

Fig. 7. Comfort zones, recommendations, and limit conditions of the floor heating (Nagoya Institute of Technology).

cooling were also conducted (Kimura et al., 1988d).

\section{9) Nagoya Institute of Technology (See Fig. 7)}

Choi (1990) reported a field survey on thermal environments in a Korean apartment house fitted with Ondol floor heating system. In order to clarify the effect of floor heating on the human body from the physiological and psychological viewpoints, a series of experiment using unclothed subjects was carried out (Choi and Horikoshi, 1991; Sakai et al., 1992; Choi et al., 1996). Based on the obtained data, upper limit of floor temperature and optimum temperature condition were proposed as shown in Fig. 7 (Choi,
1995). Effective radiation area factors and configuration factors between the body and its surroundings should be known to estimate radiative heat exchange. By a photographic method with a special fisheye lens, these factors for males and females sitting on a floor were measured and diagrams of configuration factors were presented (Miyamoto et al., 1996; Miyamoto et al., 1997). Choi et al. (1991) calculated the modified operative temperature including the effect of heat conduction between the human body and a heated floor. Miyamoto et al. (1994) extended the modified operative temperature to include the effect of inter-reflection radiation and the blocking effect of 


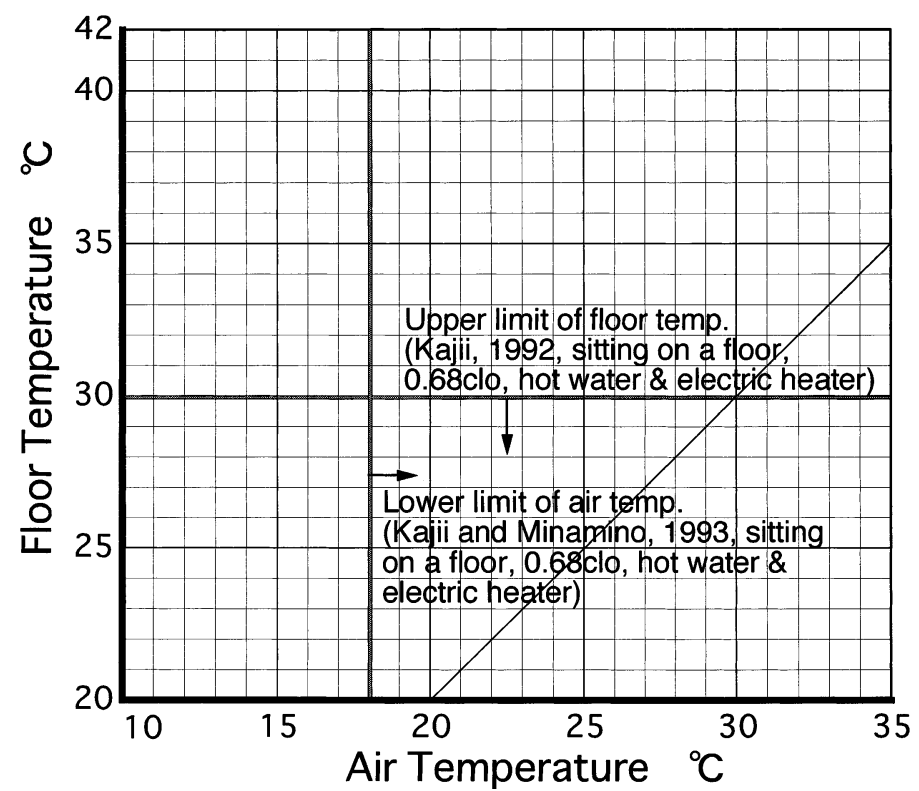

Fig. 8. Comfort zones, recommendations, and limit conditions of the floor heating (Kinki University).

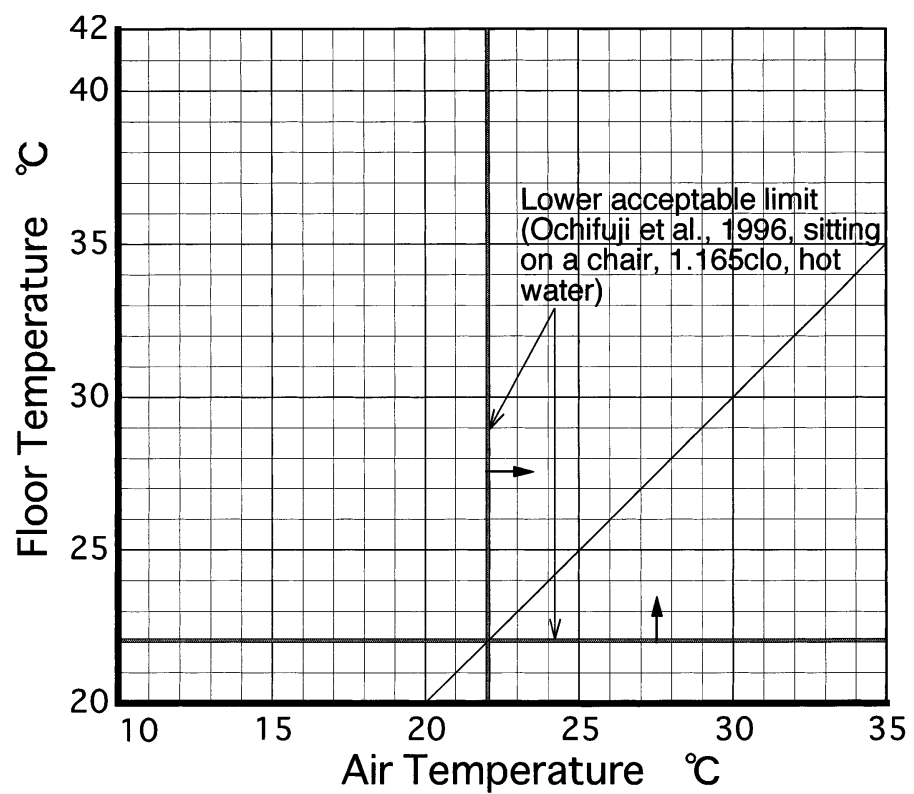

Fig. 9. Comfort zones, recommendations, and limit conditions of the floor heating (Hokkaido University).

the human body on it.

\section{0) Kinki University (See Fig. 8)}

Kajii (1990) developed a measuring instrument which used a heat flow meter to evaluate thermal sensation on the body part in contact with an object. Kajii (1992) conducted subjective experiments using panel heaters with circulating hot water, electric heaters and non-heated tatami mats. Thermal comfort of the floor heating system was examined from the physiological and psychological viewpoints (Kajii et al., 1993).
11) Hokkaido University (See Fig. 9)

This group carried out subjective experiments on a floor heating system from the viewpoint of energy saving and human acceptability in 1996. The lower acceptable limits of air temperature and floor surface temperature in a room fitted with a floor heating system in a cold region were approximately $18^{\circ} \mathrm{C}$ and $22^{\circ} \mathrm{C}$, respectively (Ochifuji et al., 1996).

\section{2) Other research groups}

Narumi et al. (1996) examined the effect of body posture under floor heating on the physiological and psychological responses by subjective experiments. 
Haccho (1983) focused on thermal comfort at the part of the body in contact with a floor. Narasaki and Iida (1985) discussed local thermal sensation under a non-uniform radiant field. Yamada et al. (1990) theoretically investigated the possibility of thermal injuries from the heat transfer point of view.

\section{Conclusions}

This paper has reviewed experimental researches regarding floor heating and its amenity using papers presented from 1975 to 1997 in Japan. Aims and findings of 12 research groups were presented. In addition, comfort zones, recommendations and limit conditions for the human body using floor heating were compared under the combination of air temperature and floor temperature. The next step is to integrate the above mentioned research findings for the benefit of architects, engineers and occupants. However, it is difficult to determine one comfort zone for floor heating because the experimental conditions (body posture, clo value, heat source) in each study are different. Therefore, a thermal index for floor heating fitted to any conditions is desired. The development of the index requires a theoretical approach based on the heat balance between human body and its environment. The index suitable for evaluation of floor heating is the modified operative temperature proposed by the Nagoya Institute of Technology group, which involved the effect of thermal radiation from a heated floor surface and heat conduction from a contacted floor. To apply the modified operative temperature to any conditions, it is necessary to prepare various values concerning the human body on each posture, namely, contact areas between human body and a floor, configuration factors between human body and its surroundings, and effective radiation area ratios. It is a way for establishing one comfort zone for floor heating to evaluate previous research results using the modified operative temperature as a scale. The index based on the heat balance can be applied to not only floor heating but also asymmetric and non-uniform thermal environment. Finally, culture and life style of people who use floor heating system should be considered, when these research findings are applied to the practice.

\section{References}

All papers were written in Japanese except one paper (Kim, B. et al., 1990).

Bogaki, K. (1985) 'Effect of thermal radiation on human comfort and sensation', SHASE, Vol. 59, No. 4, pp. 25-31.

Bogaki, K. (1986) 'Thermal comfort effects and acceptable ranges of floor heating in dwellings', Proceedings of The Tenth Symposium on Man-Thermal Environment Sys- tem, pp. 291-294.

Bogaki, K. and Osawa, H. (1990) 'Experimental study on the effect of floor heating on thermal comfort (part 3)', Summaries of Technical Papers of Annual Meeting SHASE, pp. 1233-1236.

Bogaki, K. (1991) 'Experimental study on the effect of floor heating on thermal comfort (part IV) Evaluation of floor surface materials and heating systems', Summaries of Technical Papers of Annual Meeting SHASE, pp. 161-164.

Bogaki, K. (1994) 'Experimental study on the effect of floor heating on thermal comfort (part VI) Examination of comfort and optimum conditions for floor heating', Summaries of Technical Papers of Annual Meeting SHASE, pp. 1297-1300.

Choi, Y. S. (1990) 'Field survey on thermal environments of apartment house in Korea', Summaries of Technical Papers of Annual Meeting SHASE, pp. 1229-1132.

Choi, Y. S. and Horikoshi, T. (1991) 'Influence of floor temperature upon the human skin temperature and thermal sensation', Summaries of Technical Papers of Annual Meeting SHASE, pp. 845-849.

Choi, Y. S., Horikoshi, T. and Yasuda, T. (1991) 'Indication method on the effect of floor temperature upon the human skin temperature and thermal sensation', Summaries of Technical Papers of Annual Meeting AIJ, pp. 741-742.

Choi, Y. S. (1995) 'Combined effect of air and heated floor temperature on man in Japanese sitting posture', Doctoral thesis, Nagoya Institute of Technology, Japan.

Choi, Y. S., Horikoshi, T., Miyamoto, S. and Mizutani, A. (1996) 'Combined effect of air and heated floor temperature on man in Japanese sitting posture', Transactions of AIJ, No. 480, pp. 7-14.

Emura, K. and Saito, H. (1985) 'Experimental study on the relationship between sole temperatures and body temperatures or thermal sensations with floor heating', Transactions of AIJ, Vol. 353, pp. 21-31.

Emura, K. (1990) 'A study on thermal sensation and comfort under the floor heating system — part 1: Permissible surface temperature for floor heating-survey-', Summaries of Technical Papers of Annual Meeting SHASE, pp. 1237-1240.

Emura, K. (1993) 'A study on thermal sensation and comfort under the floor heating system (part VI) Necessity of data base and its application', Summaries of Technical Papers of Annual Meeting SHASE, pp. 1-4.

Emura, K., Zheng, H. and Oyama, M. (1993) 'A study on thermal sensation and comfort under the floor heating system (part VII) A summary of experiments contained data base', Summaries of Technical Papers of Annual Meeting SHASE, pp. 5-8.

Enomoto, H., Kubo, H., Isoda, N. and Yanase, T. (1994) 'An experimental study of the effect of radiant heating on the elderly in winter (part 3) - Physical effects and conditions of the thermal environment-', Summaries of Technical Papers of Annual Meeting AIJ, pp. 349-350.

Fukai, K. and Emura, K. (1996) 'Examination of floor contact temperature and temperature sensation on floor heating systems with different thermal resistances by subjec- 
tive experiments', Summaries of Technical Papers of Annual Meeting SHASE, pp. 1153-1156.

Fukai, K. (1997) 'Thermal physiological and psychological responses to cooling floor -Floor contact temperature and thermal comfort in sitting posture on floor-', Summaries of Technical Papers of Annual Meeting SHASE, pp. 73-76.

Fukai, K. and Emura, K. (1997) 'Estimation of floor temperature under floor heating system -Examination of floor contact temperature and temperature sensation and comfort sensation-', Summaries of Technical Papers of Annual Meeting AIJ, pp. 403-404.

Haccho, M. (1983) 'A study on contact thermal comfort in thermal environment', Summaries of Technical Papers of Annual Meeting AIJ, pp. 163-164.

Hirayama, K., Kobayashi, Y., Horikoshi, T., Tsuchikawa, T. and Kurazumi, Y. (1984) 'Influence of air and floor temperatures upon the human body. - In the case of clothed young male subjects in sedentary posture during summer and winter periods-', Summaries of Technical Papers of Annual Meeting AIJ, pp. 911-912.

Hirayama, K., Horikoshi, T., Kobayashi, Y., Tsuchikawa, T. and Kurazumi, Y. (1985) 'Influence of air and floor temperature upon the human body. Part 2. - In the case of clothed and nude young male subjects in sedentary posture during winter period-', Summaries of Technical Papers of Annual Meeting AIJ, pp. 555-556.

Hori, Y., Ito, N., Sunaga, N. and Muro, K. (1997) 'Evaluation of thermal comfort in a non-uniform thermal environment - Effect of floor temperature on thermal comfort and prediction of thermal comfort on the basis of local thermal sensation-', Transactions of AIJ, No. 501, pp. 37-44.

Inoue, K., Kobayashi, Y. and Isoda, N. (1975), AIJ Kanto Chapter Architectural Research Meeting, pp. 89-90.

Isoda, N. (1982), Japanese Journal of Biometeorology, 19(3), p. 75.

Isoda, N., Kubo, H., Hayakawa, K., Kim, B., Kaku, Y. and Yanase, T. (1986a) 'The effect of floor temperature on the human body', Proceedings of The 10th Symposium on Man-Thermal Environment System, pp. 128-131.

Isoda, N., Kubo, H., Hayakawa, K. and Yanase, T. (1986b) 'On the effect of floor heating temperature on the human body', Summaries of Technical Papers of Annual Meeting AIJ, pp. 949-950.

Isoda, N., Kubo, H. and Yanase, T. (1996) 'Effects of floor heating and hot-air heating on human body', Summaries of Technical Papers of Annual Meeting AIJ, pp. 373374.

Ito, N., Nakagawa, Y. and Mitsui, S. (1976), Summaries of Technical Papers of Annual Meeting AIJ, pp. 445-446.

Ito, N., Sunaga, N. and Muro, K. (1985) 'An experimental analysis on the influence of asymmetric radiation on thermal comfort', Summaries of Technical Papers of Annual Meeting AIJ, pp. 519-520.

Ito, N., Sunaga, N., Kabata, K. and Muro, K. (1986a) 'A study of radiant factor for thermal comfort on heating indoor climate — part 1-', Summaries of Technical Papers of Annual Meeting AIJ, pp. 951-952.

Ito, N., Sunaga, N., Muro, K. and Kabata, K. (1986b) 'A study of radiant factor for thermal comfort on heating indoor climate - part 2-', Summaries of Technical Papers of Annual Meeting AIJ, pp. 953-954.

Ito, N., Sunaga, N., Kabata, K. and Muro, K. (1987a) 'Research on radiation factor evaluation for indoor heating environment: part 1 confirmation of basic items', Summaries of Technical Papers of Annual Meeting AIJ, pp. 353-354.

Ito, N., Sunaga, N., Kabata, K. and Muro, K. (1987b) 'Research on radiation factor evaluation for indoor heating environment: part 2 influence of asymmetric radiation', Summaries of Technical Papers of Annual Meeting AIJ, pp. 355-356.

Ito, N., Ishino, H., Otsuka, J. and Sasaki, M. (1989) 'An experimental base study on radiant cooling from ceiling', Summaries of Technical Papers of Annual Meeting AIJ, pp. 893-894.

Ito, N., Sunaga, N., Hori, Y., Osawa, M., Kurosaki, Y. and Suzuki, T. (1993a) 'Experimental study on thermal comfort caused by the combination with the floor surface temperature and the room air temperature in winter. Part 1. Consideration of thermal comfort on basis of subject's votes', Summaries of Technical Papers of Annual Meeting SHASE, pp. 77-80.

Ito, N., Sunaga, N., Hori, Y. and Osawa, M. (1993b) 'Experimental study on thermal comfort caused by the combination with the floor surface temperature and the room air temperature in winter. Part 2. Predictive formula for thermal comfort votes calculated by the floor surface temperature and the room air temperature', Summaries of Technical Papers of Annual Meeting SHASE, pp. 81-84.

Ito, N., Sunaga, N., Hori, Y. and Nagai, C. (1994a) 'Study on estimation of thermal comfort for different heating systems - part. 1 consideration of thermal sensation and local thermal sensation-', Summaries of Technical Papers of Annual Meeting SHASE, pp. 1317-1320.

Ito, N., Sunaga, N., Hori, Y. and Nagai, C. (1994b) 'Study on estimation of thermal comfort for different heating systems — part. 2 the equivalent thermal comfort line by the combination with floor temperature and room temperature-', Summaries of Technical Papers of Annual Meeting SHASE, pp. 1321-1324.

Ito, N., Sunaga, N., Muro, K. and Hori, Y. (1995) 'Study on estimation of thermal comfort for different heating systems - part. 3 Consideration of thermal sensation and thermal comfort in case of sitting on the floor-', Summaries of Technical Papers of Annual Meeting SHASE, pp. 1241-1244.

Kabata, K., Ito, N., Sunaga, N. and Muro, K. (1989) 'Research on radiation factor evaluation for indoor heating environment: part 5 estimate method including radiation factor', Summaries of Technical Papers of Annual Meeting AIJ, pp. 895-896.

Kabata, K. and Ito, N. (1993) 'Research on optimum space temperature comparison for heating system. Part II', Summaries of Technical Papers of Annual Meeting AIJ, pp. 1387-1388.

Kajii, H. (1990) 'Thermoesthesiometer with heat transducer', Summaries of Technical Papers of Annual Meet- 
ing AIJ, pp. 859-860.

Kajii, H. (1992) 'A study on the thermal comfort sensation and floor temperature', Proceedings of The 16th Symposium on Man-Thermal Environment System, pp. 14-17.

Kajii, H. and Minamino, O. (1993) 'A study on thermal sensation and floor heating', Summaries of Technical Papers of Annual Meeting SHASE, pp. 73-76.

Kato, H., Ito, N., Sunaga, N., Suzuki, H., Kurosaki, Y., Hori, Y. and Nagai, C. (1994) 'Experimental study of the influence of cold radiation on thermal comfort. - The comparison of thermal comfort and thermal sensation by two radiant cooling method at the case of equal OT-', Summaries of Technical Papers of Annual Meeting AIJ, pp. 341-342.

Kato, H., Ito, N., Sunaga, N., Suzuki, H., Kurosaki, Y., Hori, Y. and Nagai, C. (1995) 'Analysis of the difference of thermal sensation and thermal comfort caused by the different sitting positions on floor cooling condition. - The difference between sitting on an chair and sitting on the floor-', Summaries of Technical Papers of Annual Meeting AIJ, pp. 393-394.

Kawashima, Y., Gotoh, S. and Oohira, M. (1982) 'A study of the floor heating system', Proceedings of The 6th Symposium on Man-Thermal Environment System, pp. 61-64.

Kim, B., Isoda, N. and Yanese, T. (1987) 'On the effect of floor heating temperature on the human body (part 2)', Summaries of Technical Papers of Annual Meeting AIJ, pp. 345-346.

Kim, B., Isoda, N. and Yanase, T. (1989) 'Experimental study on the influence of human body on the floor heating (part 4)', Summaries of Technical Papers of Annual Meeting AIJ, pp. 891-892.

Kim, B., Isoda, N. and Yanase, T. (1990) 'Influence of floor heating temperature on the human body seated on the floor - In the case of electric floor heating system-', Transactions of AIJ, No. 417, pp. 19-29. (in English)

Kimura, K., Tanabe, S., Imabeppu, S., Hara, T., Akimoto, T., Ito, A., Sugiura, S. and Fujino, K. (1987) 'Effects of floor temperature on subjective thermal comfort', Summaries of Technical Papers of Annual Meeting AIJ, pp. 349-350.

Kimura, K., Tanabe, S., Fujino, K., Tamiya, K., Inoue, U., Akimoto, T. and Iwashita, T. (1988a), Summaries of Technical Papers of Annual Meeting SHASE, pp. 325328.

Kimura, K., Tanabe, S., Fujino, K., Tamiya, K., Inoue, U., Akimoto, T. and Iwashita, T. (1988b), Summaries of Technical Papers of Annual Meeting SHASE, pp. 329332.

Kimura, K., Tanabe, S., Fujino, K., Tamiya, K., Inoue, U., Akimoto, T. and Iwashita, T. (1988c) Summaries of Technical Papers of Annual Meeting SHASE, pp. 333336.

Kimura, K., Tanabe, S., Imabeppu, S., Akimoto, T., Fujino, K., Iwashita, T., Tamiya, K., Tanimoto, J. and Ushiyama, M. (1988d) 'Effects of floor cooling on subjective thermal comfort', Summaries of Technical Papers of Annual Meeting AIJ, pp. 731-732.

Kobayashi, Y., Kurazumi, Y., Horikoshi, T., Tsuchikawa, T.,
Hirayama, K., Miwa, E. and Harada, Y. (1986) 'Influence of asymmetric thermal radiation fields upon the human body. Part 3 - In the case of constant operative temperature-', Summaries of Technical Papers of Annual Meeting AIJ, pp. 943-944.

Kurazumi, Y., Horikoshi, T., Kobayashi, Y., Tsuchikawa, T. and Hirayama, K. (1985) 'Influence of asymmetric thermal radiant fields upon the human body: part 2 - In the case of constant operative temperature-', Summaries of Technical Papers of Annual Meeting AIJ, pp. 523-524.

Lee, J. Y., Isoda, N., Kubo, H. and Yanase, T. (1997a) 'The effect of air and heated floor temperature of system upon the human body (part 1) In the cases of sitting on a floor and a chair and lying on one's back', Summaries of Technical Papers of Annual Meeting AIJ, pp. 817-818.

Lee, J. Y., Mitsuda, M., Isoda, N. and Kubo, H. (1997b) 'The effect of the difference position on the human body with floor cooling system in summer condition. Part 1 . The influence of the mean skin temperature, the thermal comfort and sensation', Summaries of Technical Papers of Annual Meeting SHASE, pp. 1089-1092.

Mitsuda, M., Lee, J. Y. And Isoda, N. (1997) 'The effect of the difference position on the human body with floor cooling system in summer condition. - Part 2 . The influence of the part of the body in contact with floor-', Summaries of Technical Papers of Annual Meeting SHASE, pp. 1093-1096.

Mitsumine, Y., Shimizu, A., Kamata, M. and Bogaki, K. (1985) 'Fundamental studies on thermal comfort (part 6) Effect of radiation on thermal comfort in winter', Summaries of Technical Papers of Annual Meeting AIJ, pp. 551-552.

Mitsumine, Y., Shimizu, A., Kamata, M. and Chida, Y. (1986) 'Fundamental studies on thermal comfort (part 9) Estimation of nonuniform environment', Summaries of Technical Papers of Annual Meeting AIJ, pp. 957-958.

Miyamoto, S., Choi, Y. S., Araki, K., Mizutani, A. and Horikoshi, T. (1994) 'Thermal environmental index including the effect of radiation interchange and heat conduction', Summaries of Technical Papers of Annual Meeting SHASE, pp. 989-992.

Miyamoto, S., Taniguchi, Y., Choi, Y. S., Tsuchikawa, T. and Horikoshi, T. (1996) 'The effective radiation area and configuration factor for the person sitting on a floor', Transactions of AIJ, No. 479, pp. 27-33.

Miyamoto, S., Tsuchikawa, T., Horikoshi, T. and Mizutani, A. (1997) 'Configuration factor in case of radiant transfer is blocked by the human body sitting on the floor', Transactions of AIJ, No. 497, pp. 33-38.

Narasaki, M. and Iida, T. (1985) 'A study on regional thermal sensation under nonuniform radiant field', Summaries of Technical Papers of Annual Meeting AIJ, pp. 521-522.

Narumi, D., Kurazumi, Y., Matsubara, N. and Nagano, K. (1996) 'The influence of different postures on the human physiological and psychological responses under floor heating system -Comparison of postures among "Sedentary", "Standing", "Sitting Upright" and "Lying on the floor"-', Proceedings of The 20th Symposium on Human-Environment System, pp. 129-132. 
Ochifuji, K., Yokoyama, S., Nagano, K., Nakamura, M., Hamada, Y., Asagiri, D., Hirai, K., Aoki, T. and Isaka, M. (1996) 'Experiments on low temperature floor heating for energy saving and human acceptability (part 3) Subjective experiments on human acceptability', Summaries of Technical Papers of Annual Meeting SHASE, pp. 665-668.

Okada, M., Isoda, N. and Yanase, T. (1981), Summaries of Technical Papers of Annual Meeting AIJ, pp. 681-682.

Oyama, M. and Emura, K. (1992) 'A study on thermal and comfort under the floor heating system', Summaries of Technical Papers of Annual Meeting AIJ, pp. 993-994.

Oyama, M., Zheng, H. and Emura, K. (1993a) 'Thermal sensation and comfort under the floor heating system', Summaries of Technical Papers of Annual Meeting AIJ, pp. 1051-1052.

Oyama, M., Emura, K. and Zheng, H. (1993b) 'A study on thermal sensation and comfort under the floor heating system (part VIII) Contents of data base', Summaries of Technical Papers of Annual Meeting SHASE, pp. 9-12.

Sakai, K., Choi, Y. S., Umemura, S., Horikoshi, T. and Mizutani, A. (1992) 'The effect of air and floor temperature on the human skin temperature, thermal sensation and heat balance', Summaries of Technical Papers of Annual Meeting AIJ, pp. 999-1000.

Shimizu, A., Mitsumine, Y., Kamata, M. and Bogaki, K. (1986) 'Fundamental studies on thermal comfort (part 8) Physiological analysis of thermal sensational vote', Summaries of Technical Papers of Annual Meeting AIJ, pp. 955-956.

Sunaga, N., Ito, N., Komano, K., Hori, Y and Yamanaka, S. (1992) 'Study on the relationship between floor surface temperature and room air temperature on radiant floor heating from the view point of thermal comfort: part 1 Analysis of the thermal comfort area using the data of previous report', Summaries of Technical Papers of Annual Meeting AIJ, pp. 995-996.

Tan, H., Kuwasawa, Y. and Kamata, M. (1990) 'A study on thermal comfort of floor heating - effect of floor heating system and convection heating on thermal comfort-', Summaries of Technical Papers of Annual Meeting SHASE, pp. 1225-1228.

Tan, H., Kuwasawa, Y. and Kamata, M. (1991) 'A study on comfort of floor heating (part 2) On comfort combination of floor surface temperature and air temperature on floor heating system', Summaries of Technical Papers of Annual Meeting SHASE, pp. 165-168.

Tan, H., Kuwasawa, Y. and Kamata, M. (1993) 'A study on human comfort by floor heating (part 4) Results of sub- jective experiment and evaluation of thermal comfort', Summaries of Technical Papers of Annual Meeting SHASE, pp. 85-88.

Tan, H., Okikura, M., Kuwasawa, Y., Kamata, M. and Matsui, I. (1994) 'A study on comfort including contact thermal sensation on floor heating (part 2) Comfort combination of floor surface temperature and air temperature', Summaries of Technical Papers of Annual Meeting SHASE, pp. 1289-1292.

Tan, H., Kuwasawa, Y. and Kamata, M. (1995) 'A study on human comfort by floor heating (part 5) - Effect of cold draft-', Summaries of Technical Papers of Annual Meeting SHASE, pp. 1297-1300.

Tanabe, S. and Kimura, K. (1986) 'Pilot experiment on thermal comfort requirements for adults during summer season in Japan', Transactions of AIJ, No. 368, pp. 31-41.

Tanaka, S., Shimizu, A., Kamata, M. and Bogaki, K. (1984) 'Fundamental studies on thermal comfort (part 4) Effect of convection and radiation on thermal comfort', Summaries of Technical Papers of Annual Meeting AIJ, pp. 933-934.

Yagou, K., Emura, K., Oyama, M., Tanaka, T. and Taguchi, K. (1991) 'A study on thermal sensation and comfort under the floor heating system (part 2)', Summaries of Technical Papers of Annual Meeting SHASE, pp. 829-832.

Yamada, Y., Tanaka, T., Ishiguro, H. and Yamashita, M. (1990) 'Theoretical study of thermal injury by a warming mat', Proceedings of The 14th Symposium on ManThermal Environment System, pp. 114-117.

Yamaguchi, K., Kobayashi, Y., Horikoshi, T., Hirayama, K., Kurazumi, Y. and Sakai, K. (1985) 'Effect of radiant heating/cooling systems on the human body working in the office space. Part 1. Experiment for radiant heating -clothed male subject in the wind tunnel with artificial climate', Summaries of Technical Papers of Annual Meeting AIJ, pp. 515-516.

Zhang, L., Emura, K., Zheng, H. and Nakane, Y. (1996) 'Study on the thermal environment assessment under floor heating system - Considering the admirable and permissible floor surface temperature-', Summaries of Technical Papers of Annual Meeting SHASE, pp. 1149-1152.

Zheng, H., Emura, K., Fukai, K. and Nakane, Y. (1995) 'Influence of blood flow on contact temperature with floor heating', Proceedings of The 19th Symposium on Human-Environment System, pp. 10-13. 